\title{
Early and Late Strength Characterization of Portland Cement Containing Calcined Low-Grade Kaolin Clay
}

\author{
Mark Bediako, ${ }^{1}$ S. K. Y. Gawu, ${ }^{2}$ A. A. Adjaottor, ${ }^{3}$ and John Solomon Ankrah ${ }^{1}$ \\ ${ }^{1}$ CSIR-Building and Road Research Institute, Kumasi, Ghana \\ ${ }^{2}$ Geological Engineering Department, Kwame Nkrumah University of Science and Technology, Kumasi, Ghana \\ ${ }^{3}$ Materials Engineering Department, Kwame Nkrumah University of Science and Technology, Kumasi, Ghana
}

Correspondence should be addressed to Mark Bediako; b23mark@yahoo.com

Received 15 January 2016; Revised 15 March 2016; Accepted 17 March 2016

Academic Editor: İlker Bekir Topçu

Copyright (C) 2016 Mark Bediako et al. This is an open access article distributed under the Creative Commons Attribution License, which permits unrestricted use, distribution, and reproduction in any medium, provided the original work is properly cited.

\begin{abstract}
Heat treated low-grade kaolin clays are now considered as a suitable pozzolanic material to metakaolins. However their suitability as a good pozzolanic material depends on the geochemistry and structure of the clay which is usually influenced by the geographical environment. This study investigated a low-grade kaolin clay from Nyamebekyere in the Ashanti Region of Ghana. The influence of the calcined material on the early and late strength development of Portland cement was analyzed. The early 3-and 7-day strength as well as the late 28 -day strength of Portland cement replaced with $20 \%$ by weight of the calcined material yielded the optimum strength values. Further analysis using Solid State Magic Angle Spinning Nuclear Magnetic Resonance (Ss MAS NMR) probed into the Aluminium (Al) environment to detect the presence and nature of $\mathrm{Al}$ hydrates using the optimum mixture proportion. The Ss MAS NMR results showed that the strength enhancement of the optimum mixture was due to the growth of stable monosulphate compounds at the octahedral environment resulting from metastable aluminate phases at the tetrahedral environment. For greater reliability on concrete strength performance, the study recommends the use of $20 \%$ calcined clay of Nyamebekyere clay as Portland cement replacement.
\end{abstract}

\section{Introduction}

Portland cement is an important building material which supports the concrete industry for infrastructural and residential development. Concrete is the second most widely consumed material after water. Research has shown that not only Portland cement is used to prepare durable concrete but also mixture between Portland cement and supplementary cementitious materials (SCMs) is possible. SCMs that have been used in concrete include pozzolanic materials such as fly ash, slag, silica fume, and metakaolin [1-3]. Usually SCMs are used to replace between $20 \%$ and $40 \%$ of Portland cement by weight. The utilization of SCMs as partial replacement of cement is known to enhance strength of concretes as well as improving the durability of concrete whilst minimizing cement cost.

Metakaolins are SCMs produced from the calcination of high grade kaolin clays $[4,5]$. High grade kaolin clays are of limited quantities on the earth crust. This therefore makes metakaolin an expensive construction material. However the earth crust contains huge quantities of medium to low-grade kaolin clays. High grade kaolin clays are those clays with kaolinite content greater than $65 \%$, whereas medium and low grades have their kaolinite content between $40 \%$ and $65 \%$ and below $40 \%$, respectively $[6,7]$. The availability of lowgrade kaolin clays compared to high grade ones has attracted the attention of researchers into developing pozzolans from clays of such nature. Authors including Fernandez et al. [8], He et al. [9], and Maia et al. [4] have shown that calcined low-grade kaolinitic clays improve strength and durability of concretes better than Portland cement concretes. However the reactivity of these calcined clays depends on the geographical location which also influences their structure and chemistry. The variance in structure and chemistry of a clay from a particular location provide the need for investigations on regional or local clay materials as a suitable SCM. 
Clays are very abundant in Ghana; however their processing and usage as a pozzolan remain a challenge [10]. Already there are some existing works in Ghana from Atiemo [11] and Bediako and Atiemo [12] that used Mankranso, Hwereso, and Mfensi clay to produce pozzolan. All these mentioned areas in Ghana have huge deposits of clay. Producing pozzolan from clay is done by calcining the clay at temperatures between 600 and $900^{\circ} \mathrm{C}$ [13]. This work seeks to produce clay pozzolan from clay sourced from Nyamebekyere in the Ashanti region of Ghana. The area, Nyamebekyere, is a small farming community in Ghana with abundance of clay which is yet to be quantified. The main aim of the study is to investigate the influence of Nyamebekyere calcined clay on the early and strength properties of Portland cement mortars. Compressive strength analysis was performed on mortar specimens using a strength testing machine. The strength results were corroborated with the ${ }^{27} \mathrm{Al}$ MAS NMR studies to further explain the performance of optimum mixtures between Portland cement and calcined clay.

\section{Materials and Methods}

2.1. Materials. The materials used for the study included Portland cement, clay, sand, tap water, and a water reducer. The Portland cement was obtained from Ash grove in Chanute, Kansas. Clay was obtained from Nyamebekyere in Ashanti region. The sand used was a laboratory graded silica sand which met the ASTM C778 standard. The water reducer was of a polycarboxylate origin by the name Glenium 7500 . The tap water was sourced from the running taps in the civil laboratory of University of Missouri Kansas City (UMKC). Table 1 presents the properties of the Portland cement and clay. Figure 1 also provides the Ss MAS NMR characterization of the raw clay. The figure shows two distinct chemical shifts at $68.30 \mathrm{ppm}$ and $-0.76 \mathrm{ppm}$ which represent a tetrahedral and octahedral environments, respectively, characterizing the clay as a $1: 1$ kaolin clay. Actual clay content of about $28.4 \%$ in the Nyamebekyere clay also put the clay in the category of a low-grade kaolin clay.

\subsection{Methods}

2.2.1. Calcination of Clay. The raw clay was milled into fine particle size ranging between $150 \mu \mathrm{m}$ and $2 \mathrm{~mm}$ using a hammer mill. The milled clay was placed in a ceramic bowl and calcined using a laboratory electric furnace (Barnstead Thermolyne 6000) operated at $800^{\circ} \mathrm{C}$ for 2 hours. After twohour calcination, the furnace was switched off and allowed to cool for about 24 hours. The calcined material was collected from the bowl and sieved through the $75 \mu \mathrm{m}$ sieve size. The ones received under the sieve size were collected, added to Portland cement, and used for mortar formation.

2.2.2. Mortar Preparation and Curing. The mortar specimens were prepared in accordance with the ASTM C109 standards. The mortar specimens were prepared in batches and each batch filled three of three-gang metallic molds. The flow of the mortar prepared from Portland cement and calcined clays pozzolan mixtures was attained with the high range water
TABLE 1: Properties of Portland cement and raw clay.

\begin{tabular}{|c|c|c|}
\hline Property & $\mathrm{PC}$ & Raw clay \\
\hline \multicolumn{3}{|l|}{ Physical } \\
\hline Fineness $\left(\mathrm{m}^{2} / \mathrm{kg}\right)$ & 401.7 & \\
\hline Specific gravity & 3.13 & \\
\hline \multicolumn{3}{|l|}{ Chemical } \\
\hline $\mathrm{SiO}_{2}(\%)$ & 20.49 & 59.7 \\
\hline $\mathrm{Al}_{2} \mathrm{O}_{3}(\%)$ & 4.26 & 25.53 \\
\hline $\mathrm{Fe}_{2} \mathrm{O}_{3}(\%)$ & 3.14 & 5.22 \\
\hline $\mathrm{CaO}(\%)$ & 63.48 & 0.16 \\
\hline $\mathrm{MgO}(\%)$ & 2.11 & 1.37 \\
\hline $\mathrm{SO}_{3}(\%)$ & 2.9 & 0.07 \\
\hline $\mathrm{Na}_{2} \mathrm{O}+\mathrm{K}_{2} \mathrm{O}(\%)$ & 0.49 & 2.41 \\
\hline LOI (\%) & 2.2 & 4.5 \\
\hline \multicolumn{3}{|l|}{ Mineralogy } \\
\hline $\mathrm{C}_{3} \mathrm{~S}(\%)$ & 56 & \\
\hline $\mathrm{C}_{2} \mathrm{~S}(\%)$ & 15 & \\
\hline $\mathrm{C}_{3} \mathrm{~A}(\%)$ & 6 & \\
\hline $\mathrm{C}_{4} \mathrm{AF}(\%)$ & 9 & \\
\hline \multicolumn{3}{|l|}{ Particle size distribution (\%) } \\
\hline Clay $(<2 \mu \mathrm{m})$ & & 28.4 \\
\hline Silt $(2 \mu \mathrm{m}-0.05 \mathrm{~mm})$ & & 19.5 \\
\hline Sand $(0.05 \mathrm{~mm}-2 \mathrm{~mm})$ & & 52 \\
\hline Gravel $(>2 \mathrm{~mm})$ & & 0.1 \\
\hline
\end{tabular}

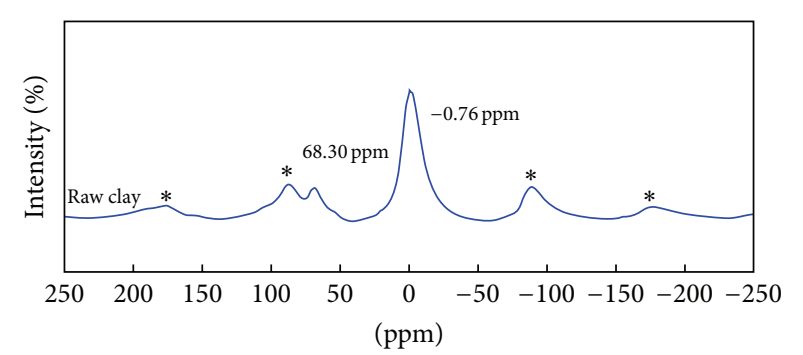

FIGURE 1: Solid state ${ }^{27} \mathrm{Al}$ MAS NMR of raw clay. ${ }^{*}$ Noise made during spinning.

reducer. Table 2 presents the mortar mixture proportions of the cement and the cement-pozzolan system. Curing of the mortar samples was performed in a lime saturated water bath for 3,7 , and 28 days.

2.2.3. ${ }^{27} \mathrm{Al}$ MAS NMR Determination. The ${ }^{27} \mathrm{Al}$ NMR was determined on binder paste. The binder paste containing calcined clay was prepared based on the optimum mortar mix proportion. The binder paste of normal consistency was prepared in accordance with ASTM C187. Tecmag Apollo Console (Houston, TX) with $8.45 \mathrm{~T}$ magnet and homebuilt, single channel, $4 \mathrm{~mm}$ wide-bore NMR probe was used to determine ${ }^{27} \mathrm{Al}$ spectra. About $90 \mathrm{mg}$ of sample was taken for each analysis and signals are represented as chemical shift value, $\delta$ : ppm. The ${ }^{27} \mathrm{Al}$ Larmor frequency was $93.074 \mathrm{MHz}$. ${ }^{27} \mathrm{Al}$ spectra were acquired with MAS spinning frequency, 
TABLE 2: Mortar mixture proportions of cement and calcined clay at $800^{\circ} \mathrm{C}$.

\begin{tabular}{|c|c|c|c|c|c|c|c|c|c|}
\hline \multirow{2}{*}{ Mix } & \multicolumn{2}{|c|}{ Content (\%) } & \multirow{2}{*}{$\mathrm{w} / \mathrm{b}$} & \multicolumn{4}{|c|}{ Mass (g) } & \multirow{2}{*}{ HRWR (\%) } & \multirow{2}{*}{ Flow } \\
\hline & Cement & Clay & & Cement & Clay Pozzo & Sand & Water & & \\
\hline Control & 100 & 0 & 0.485 & 740 & 0 & 2035 & 359 & 0.00 & 107 \\
\hline 10P800 & 90 & 10 & 0.485 & 666 & 74 & 2035 & 359 & 0.14 & 107 \\
\hline 20P800 & 80 & 20 & 0.485 & 592 & 148 & 2035 & 359 & 0.32 & 114 \\
\hline $30 \mathrm{P} 800$ & 70 & 30 & 0.485 & 518 & 222 & 2035 & 359 & 0.34 & 105 \\
\hline $40 \mathrm{P} 800$ & 60 & 40 & 0.485 & 444 & 296 & 2035 & 359 & 0.45 & 107 \\
\hline
\end{tabular}

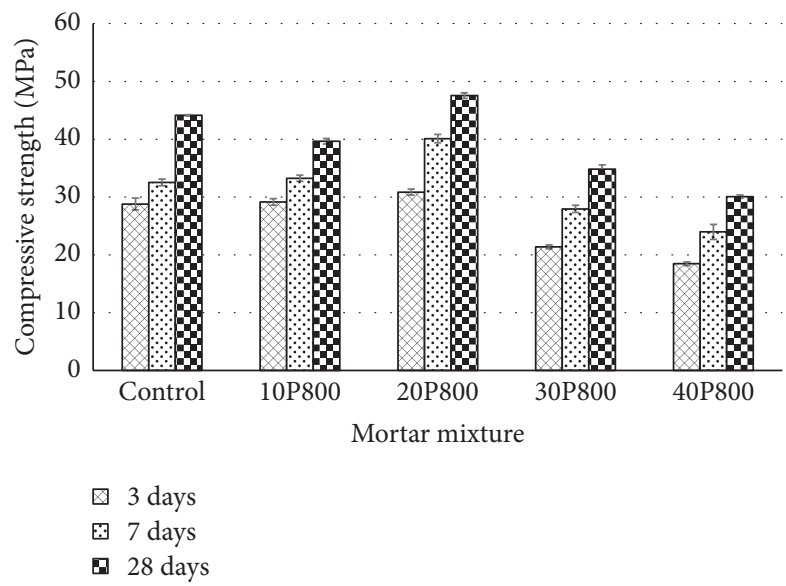

FIgURE 2: Mortar cured for 3, 7, and 28 days.

last delay, and $90^{\circ}$ pulse length of $8 \mathrm{KHz}, 1 \mathrm{~s}$, and $2.5 \mu \mathrm{s}$, respectively. Aluminum nitrate $\left[\mathrm{Al}\left(\mathrm{NO}_{3}\right)\right]$ was used as reference compound for ${ }^{27} \mathrm{Al}$. All experiments were performed at ambient temperature without any corrections for sample heating.

\section{Results and Discussions}

3.1. Early Strength. Figure 2 presents the early strength results of mortars cured at 3 and 7 days as well as the late age strength cured for 28 days. The replacement of Portland cement with $20 \%$ calcined clay at $800^{\circ} \mathrm{C}(20 \mathrm{P} 800)$ attained the maximum strength. 20P800 strength values at 3 and 7 days exceeded the control mortar by $7 \%$ and $23 \%$, respectively. This shows that the inclusion of the pozzolanic material influenced cement reactivity and performance at early ages. At the early age of 3 and 7 days, the performance of 20P800 mortar indicates that the calcined material in Portland cement behaves as a filler, accelerating Portland cement hydration. The acceleration of the hydration process generates more calcium hydroxide to react with the active silica and aluminate phases of pozzolans to produce secondary calcium aluminosilicate hydrates at early ages. The formation of these secondary products enhances strength performance.

20P800 again attained the maximum strength at 28 days. The strength value of $20 \mathrm{P} 800$ exceeded that of the control mortar by approximately $8 \%$. The enhancement of the strength of 20P800 could be attributed to pozzolanic reaction [14]. Pozzolanic reaction occurs between active silica and aluminate phases from the calcined material and the calcium hydroxide obtained from Portland cement hydration. Beyond the $20 \%$ of cement replacement by the calcined material, Portland cement strength decreased. This shows that $20 \%$ of the calcined material was enough to react with lime generated from hydrated cement. The decrease in strength beyond $20 \%$ meant that there was less lime to react with more of the silicates found in the calcined material, making the reactive silicate redundant. In such cases there will be no formation of secondary silicate hydrates $(\mathrm{CSH})$ which can enhance strength.

3.2. ${ }^{27} \mathrm{Al}$ MAS NMR Studies. Figure 3 presents the $\mathrm{Ss}{ }^{27} \mathrm{Al}$ MAS NMR results of the control cement paste and cement paste containing pozzolana (20P800). The figure shows two distinct peaks at the chemical shift of $68.14 \mathrm{ppm}$ and $7.86 \mathrm{ppm}$. The shifts at $68.14 \mathrm{ppm}$ and $7.86 \mathrm{ppm}$ indicate the tetrahedral $\left(\mathrm{Al}^{[\mathrm{iv}]}\right)$ and octahedral $\left(\mathrm{Al}^{[\mathrm{vij}}\right)$ coordinated environment, respectively. Usually for hydrated cement samples, there is a chemical shift from the tetrahedral environment to the octahedral environment due to polarization of hydrated materials. The studies of Skibsted et al. [15] and Anderson et al. [16] have shown that chemical shift between 8 and $11.8 \mathrm{ppm}$ corresponds to monosulphates, whereas chemical shifts between 66 and $72 \mathrm{ppm}$ correspond to $\mathrm{Al}$ replacing $\mathrm{Si}$ in the tetrahedral environment $\left(\mathrm{Al}^{[\mathrm{iv}]}\right)$. The figures ( $\mathrm{a}$, $\mathrm{b}$, and c) show that the inclusion of the calcined materials in cement led to the formation of more $\mathrm{Al}$ phases in the tetrahedral environment that passed into the alkaline solution to form more stable monosulphate phases at the octahedral environment. Figures 3(a) and 3(b) showed that the calcined clay accelerated cement hydration at the early 3 and 7 days confirming the filler effect of the calcined material. This could be proven by the intensities obtained which are approximately 114 and $118 \%$ at the $\mathrm{Al}^{[\mathrm{vi}]}$ environment compared to the $100 \%$ of the control mix. At the later age of 28 days, the intensity of $20 \mathrm{P} 800$ binder paste grew to approximately $154 \%$ compared to the control. The increased formation of stable calcium aluminate and monosulphate phases at the octahedral environment at later age of 28 days show the occurrence of pozzolanic reaction. The effect of pozzolanic reaction improves strength properties of concrete. This also confirms the strength performance of 20P800 at 28 days. 


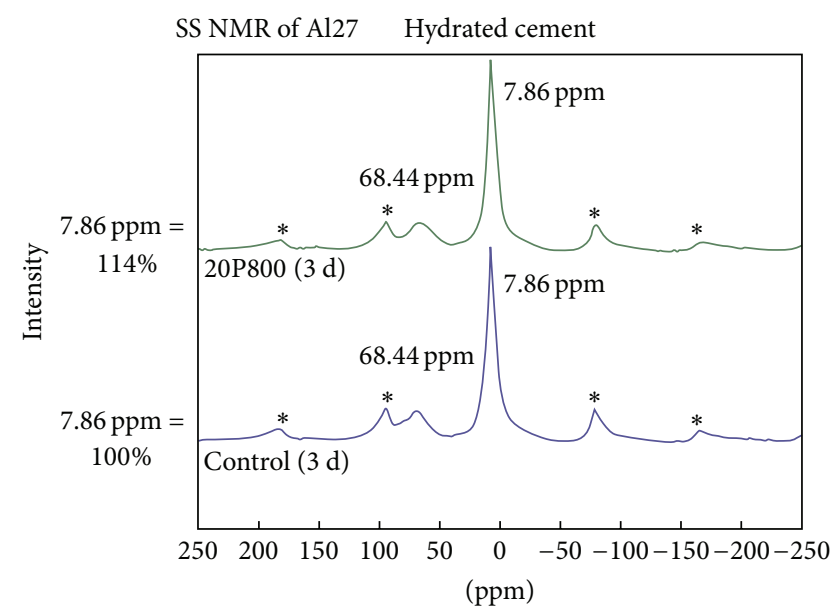

(a)

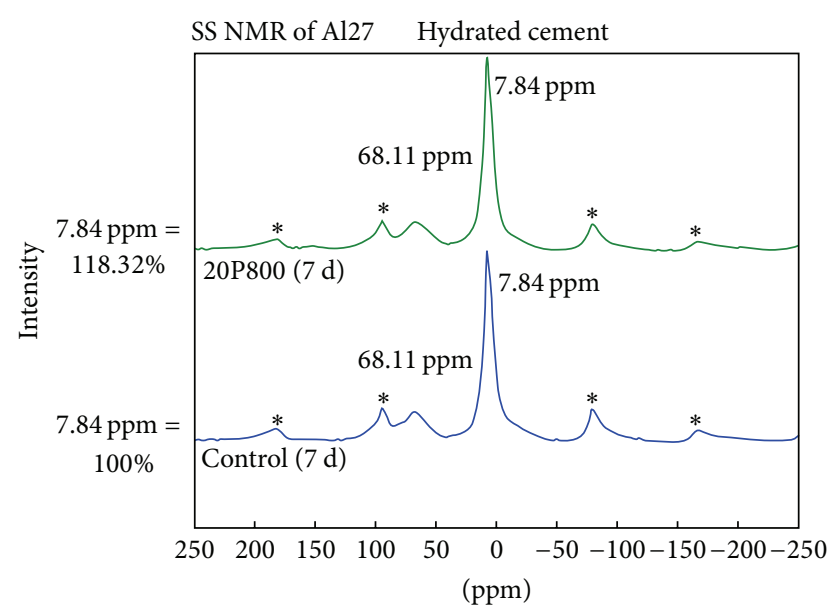

(b)

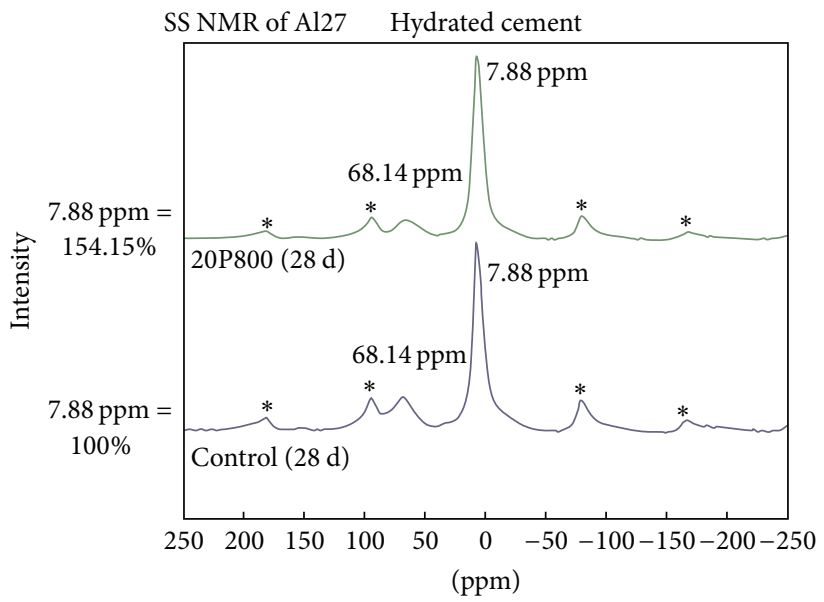

(c)

FiguRE $3:{ }^{27} \mathrm{Al}$ MAS NMR spectroscopy of hydrated cement and cement/calcined clay paste. ${ }^{*}$ Noise made during spinning.

\section{Conclusions}

The study investigated the early and late strength properties of Portland cement and Portland cement-calcined clay systems. The optimum compressive strength values obtained were corroborated with the results of ${ }^{27} \mathrm{Al}$ MAS NMR studies. From the study, the following conclusions were made:

(1) The clay as characterized by the MAS NMR and the particle size analysis was a 1:1 kaolin clay of low-grade type.

(2) The optimum compressive strength obtained for replacing Portland cement with calcined clay by weight was at $20 \%$.

(3) The calcined clay material had both a filler and pozzolanic effect.

(4) The strength improvement of the pozzolan mortars compared to the controlled mortars was due to the growth of stable monosulphates at the octahedral environment.

\section{Competing Interests}

The authors declare that they have no competing interests.

\section{References}

[1] A. Lübeck, A. L. G. Gastaldini, D. S. Barin, and H. C. Siqueira, "Compressive strength and electrical properties of concrete with white Portland cement and blast-furnace slag," Cement and Concrete Composites, vol. 34, no. 3, pp. 392-399, 2012.

[2] W. Xu, J. Xu, J. Liu et al., "The utilization of lime-dried sludge as resource for producing cement," Journal of Cleaner Production, vol. 83, pp. 286-293, 2014.

[3] B. W. Langan, K. Weng, and M. A. Ward, "Effect of silica fume and fly ash on heat of hydration of Portland cement," Cement and Concrete Research, vol. 32, no. 7, pp. 1045-1051, 2002.

[4] A. Á. B. Maia, R. S. Angélica, R. de Freitas Neves, H. Pöllmann, C. Straub, and K. Saalwächter, "Use of 29Si and 27Al MAS NMR to study thermal activation of kaolinites from Brazilian Amazon kaolin wastes," Applied Clay Science, vol. 87, pp. 189-196, 2014.

[5] C. Bich, J. Ambroise, and J. Péra, "Influence of degree of dehydroxylation on the pozzolanic activity of metakaolin," Applied Clay Science, vol. 44, no. 3-4, pp. 194-200, 2009. 
[6] A. Aras, M. Albayrak, M. Arikan, and K. Sobolev, "Evaluation of selected kaolins as raw materials for the Turkish cement and concrete industry," Clay Minerals, vol. 42, no. 2, pp. 233-244, 2007.

[7] A. Alujas, R. Fernández, R. Quintana, K. L. Scrivener, and F. Martirena, "Pozzolanic reactivity of low grade kaolinitic clays: influence of calcination temperature and impact of calcination products on OPC hydration," Applied Clay Science, vol. 108, pp. 94-101, 2015.

[8] R. Fernandez, F. Martirena, and K. L. Scrivener, "The origin of the pozzolanic activity of calcined clay minerals: a comparison between kaolinite, illite and montmorillonite," Cement \& Concrete Research, vol. 41, no. 1, pp. 113-122, 2011.

[9] C. He, E. Makovicky, and B. Osbæck, "Thermal stability and pozzolanic activity of calcined kaolin," Applied Clay Science, vol. 9, no. 3, pp. 165-187, 1994.

[10] M. Bediako, S. K. Y. Gawu, and A. A. Adjaottor, "Suitability of some Ghanaian mineral admixtures for masonry mortar formulation," Construction and Building Materials, vol. 29, pp. 667-671, 2012.

[11] E. Atiemo, "Production of pozzolana from some local claysprospects for application in housing construction," Journal of the Building \& Road Research Institute, vol. 9, no. 1-2, pp. 34-37, 2005.

[12] M. Bediako and E. Atiemo, "Influence of higher volumes of clay pozzolana replacement levels on some technical properties of cement pastes and mortars," Journal of Scientific Research and Reports, vol. 3, no. 23, pp. 3018-3030, 2014.

[13] A. Tironi, M. A. Trezza, A. N. Scian, and E. F. Irassar, "Kaolinitic calcined clays: factors affecting its performance as pozzolans," Construction \& Building Materials, vol. 28, no. 1, pp. 276-281, 2012.

[14] V. Indrawati and A. Manaf, "Mechanical strength of trass as supplementary cementing material," Journal of Physical Science, vol. 92, no. 2, pp. 51-59, 2008.

[15] J. Skibsted, E. Henderson, and H. J. Jakobsen, "Characterization of calcium aluminate phases in cements by 27AlMAS NMR spectroscopy," Inorganic Chemistry, vol. 32, no. 6, pp. 1013-1027, 1993.

[16] M. D. Andersen, H. J. Jakobsen, and J. Skibsted, "A new aluminium-hydrate species in hydrated Portland cements characterized by ${ }^{27} \mathrm{Al}$ and ${ }^{29} \mathrm{Si}$ MAS NMR spectroscopy," Cement and Concrete Research, vol. 36, no. 1, pp. 3-17, 2006. 


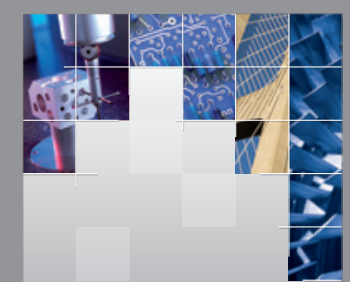

\section{Enfincering}
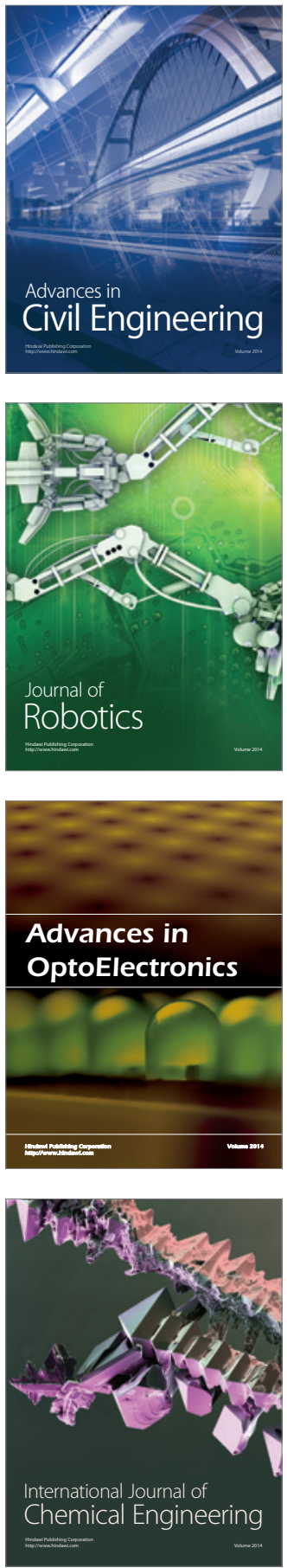

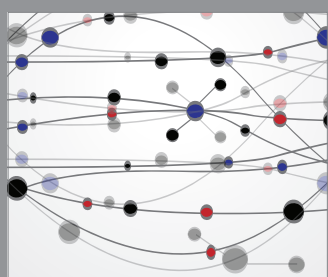

The Scientific World Journal

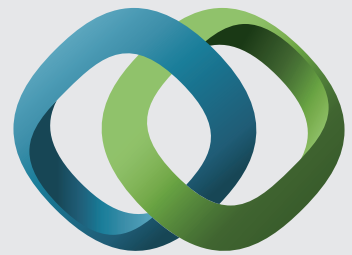

\section{Hindawi}

Submit your manuscripts at

http://www.hindawi.com
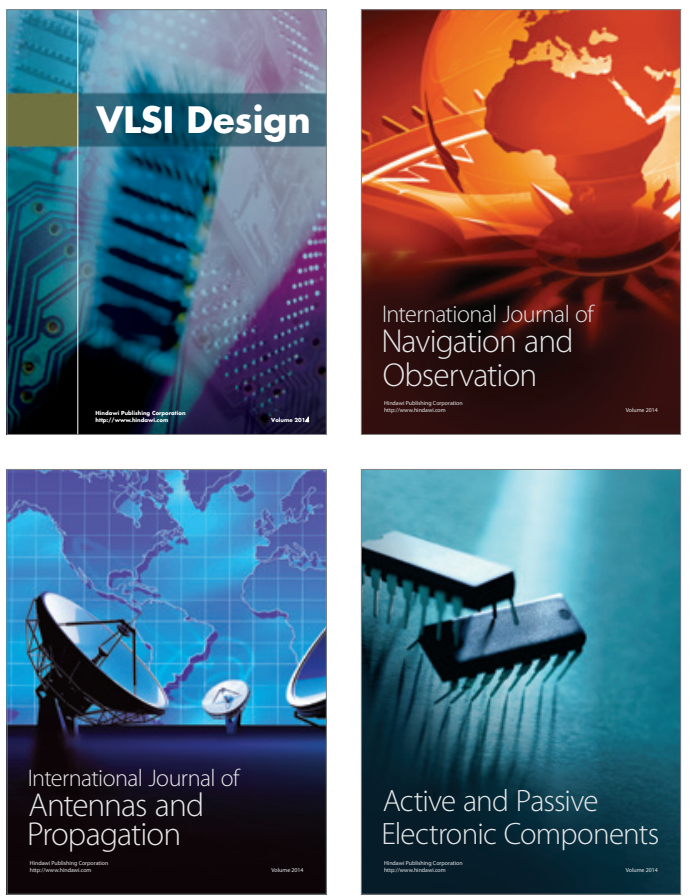
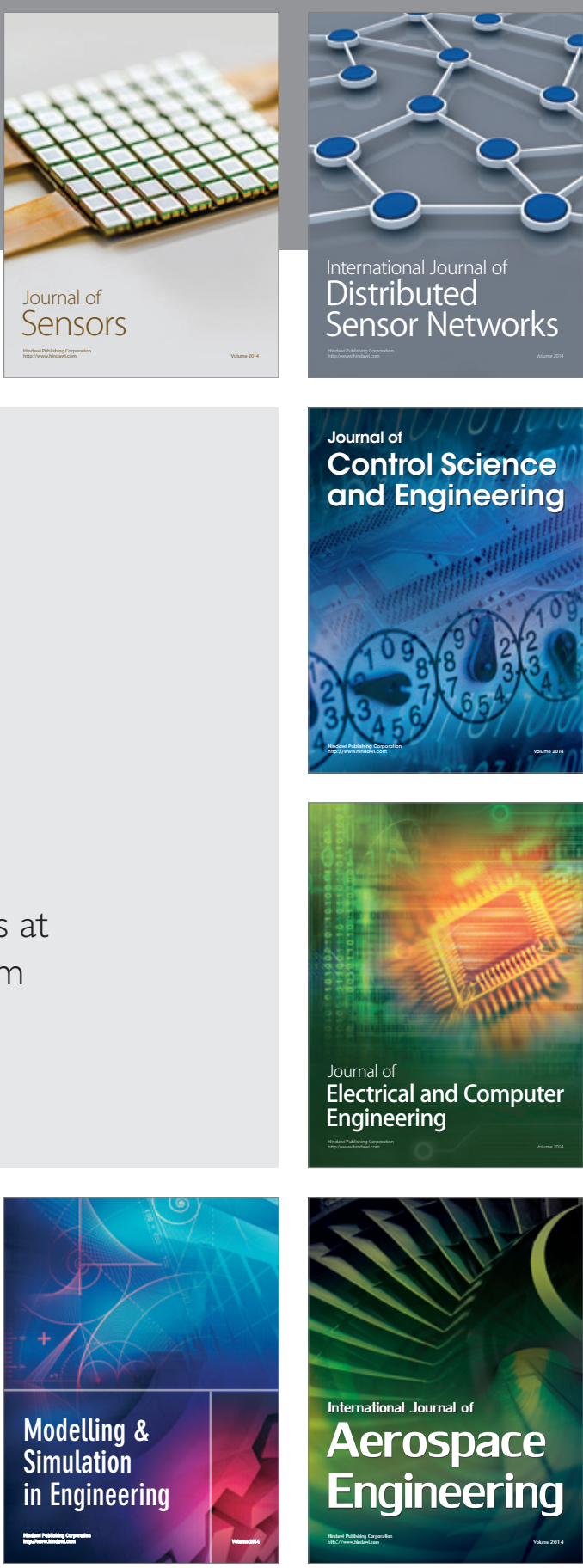

International Journal of

Distributed

Sensor Networks

Journal of

Control Science

and Engineering
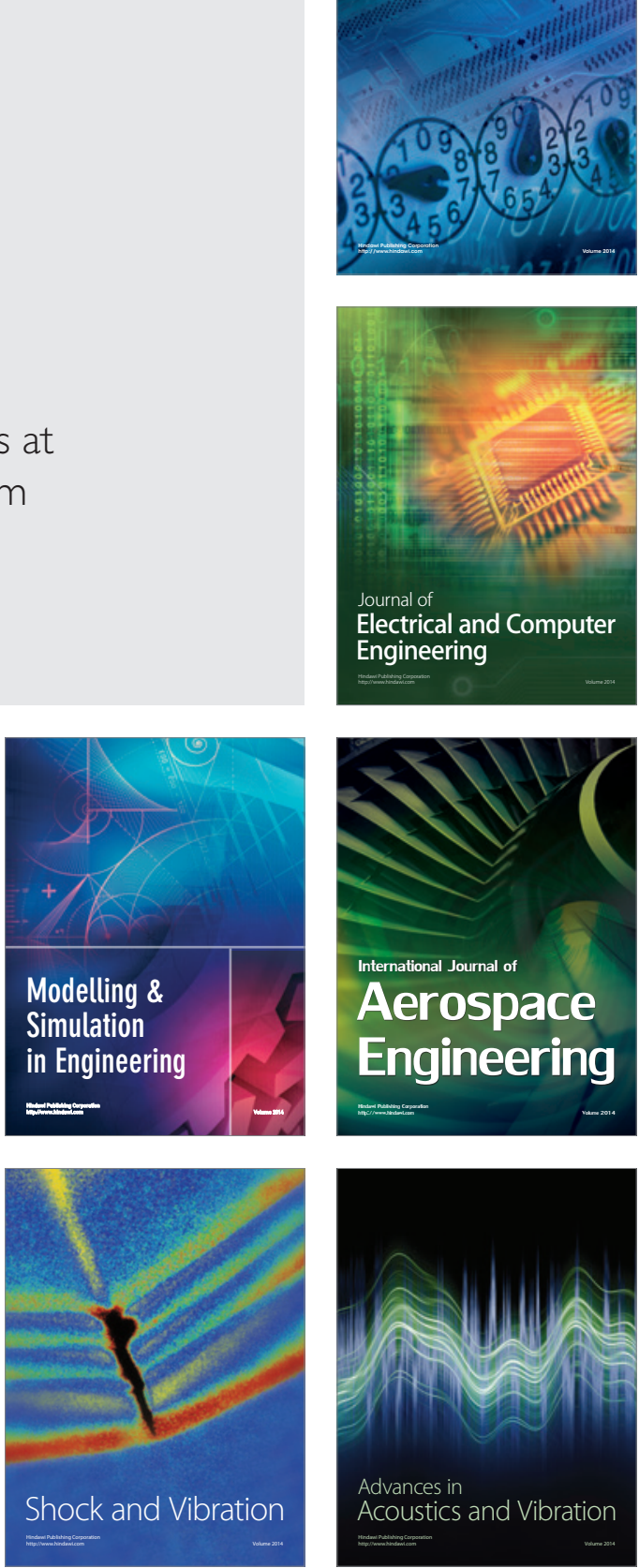